\title{
backstory
}

\section{Mopping up mercury}

\section{Paolo Gabrielli and colleagues dug deeply - and extremely cautiously — into Antarctic ice, to see whether the poles acted as a sink for mercury in the geological past.}

What was the objective of the work? Atmospheric mercury depletion events are a common seasonal occurrence at the poles - probably owing to complex chemical reactions between mercury and sea-ice-derived halogens. In this project we wanted to see whether polar mercury depletion events were also prevalent during the geological past. To do this, we made use of the ice core drilled at Dome $\mathrm{C}$ in Antarctica, where the deepest layers date back $\sim 800,000$ years. We participated in the coring that took place in the early 1990 s within the European Project for Ice Coring in Antarctica (EPICA), a collaboration of ten European nations.

What sorts of samples were you after? We wanted to know whether mercury deposition varied over the last 670,000 years, so we measured mercury concentrations in 70 sections of the EPICA Dome C ice core. Antarctic ice contains extremely low levels of mercury - down to less than one picogram per gram. Thus we had to adopt exceedingly clean procedures to avoid contamination during handling and extraordinarily sensitive instrumental techniques when analysing the ice.

\section{Did you encounter any difficulties?}

Extracting the deepest ice was the greatest challenge. The bottom of the ice pack is close to melting owing to the release of geothermal heat from the bedrock and the high pressure of the overlying $3 \mathrm{~km}$ of ice. Hence, cutting the ice becomes less and less efficient the deeper you go, and there is an increasing risk of getting the drill stuck. Operations at depth therefore had to proceed extremely slowly.

Did you encounter any dangerous situations?

Dome $\mathrm{C}$ is located in one of the remotest

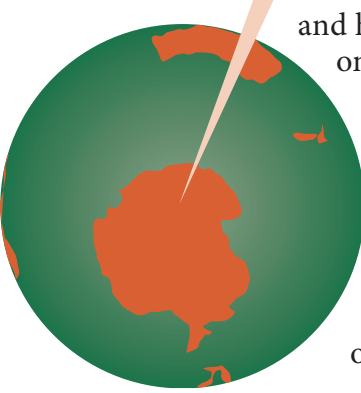
nd harshest places on Earth - the

East Antarctic plateau - where the average annual temperature is $-55^{\circ} \mathrm{C}$. What's more, for months we had to carry out potentially

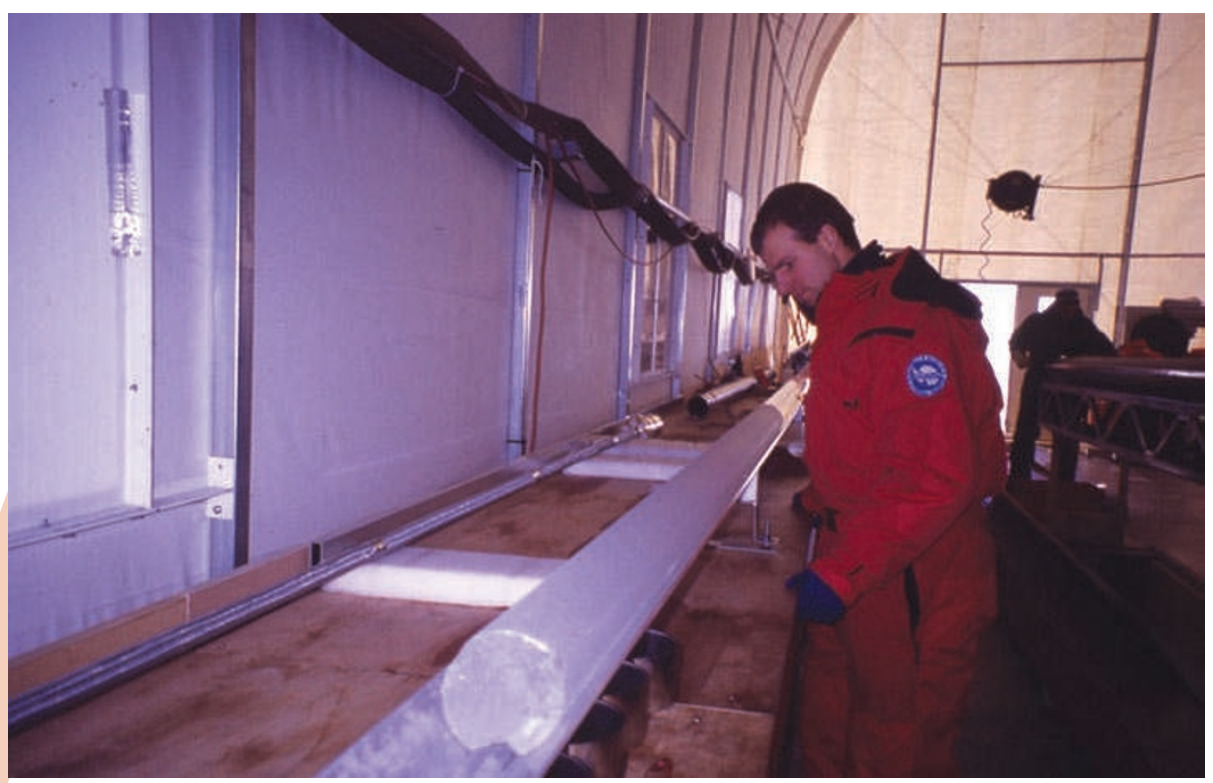

Paolo Gabrielli takes a look into the past by observing a freshly retrieved ice-core section from Dome C, Antarctica.

hazardous operations, such as using electric saws to cut the ice. The nearest hospital was in Christchurch, New Zealand, at least 24 hours away by plane. For this reason the camp's medical facility was prepared to perform delicate surgeries aimed at stabilizing seriously injured patients and making them transportable. Fortunately, none of the EPICA participants suffered any serious accidents.

\section{Any low points?}

During the 1998/1999 field season, the drill got stuck $780 \mathrm{~m}$ below the ice surface; the drill is there till this day, free to a good home. This event delayed the project by at least two years as we had to wait for a new drill to be built. And in 2003 a container of self-developed scientific instruments, designed for analysing the ice, was lost during its journey from Dome C to Europe, resulting in further delays to the program.

\section{Was it straightforward to get the} samples back to the lab?

Keeping the ice cores frozen during their transport to various European laboratories was a real challenge. Researchers often had to fly with their ice-core boxes from Dome $\mathrm{C}$ to the Antarctic coast by small planes called Twin Otters, whose cabins were kept at temperatures far below freezing point to safeguard the ice. Paradoxically, we faced the most unpleasant and extreme conditions back in the cold lab where the ice sections were decontaminated for mercury analysis - ventilators created a constant wind chill capable of exasperating even the most motivated scientist.

Did the trip give you any ideas for future research projects?

Next, Paolo Gabrielli is going to drill ice cores in the Cordillera Blanca mountain range in Peru and the Puncak Jaya mountain range in New Guinea, the latter of which is home to the last glacier in the area between the Himalaya and the Andes. One of the aims is to see whether mercury depletion events also took place in the highest mountain ranges of the tropics.

This is the Backstory to work by Paolo Gabrielli and colleagues, published on page 505 of this issue. 